\title{
PENGARUH KOMPENSASI FINANSIAL DAN NON FINANSIAL TERHADAP PRODUKTIVITAS KERJA PADA BANK SUMUT CABANG SYARIAH MEDAN
}

\author{
Ahmad Saputra ${ }^{1}$ Nina Arliz ${ }^{2}$ \\ Manajemen, STIE IBBI \\ ${ }^{1}$ Saputra_damha@yahoo.com \\ 2arliznina@yahoo.co.id
}

\begin{abstract}
This study was conducted to determine how much influence the compensation financial and non financial to increase employee productivity Bank Sumut Cabang Syariah Medan. The research method used in this study is the interview and questionnare. Type a descriptive quantitative research, and the nature of the research is the explanation. The analytical method used is multiple linear regression. The conclusion that can be drawn from the test results indicate that the compensation financial and non financial simultaneously significant effect on the increase in employee productivity Bank Sumut Cabang Syariah Medan. Based on this, the company should be able to further improve system compensation to increase employee productivity
\end{abstract}

Keywords: Compensation financial, compensation non financial, and Work Productivity

\section{PENDAHULUAN}

Sumber Daya Manusia merupakan salah satu komponen yang sangat penting untuk meningkatkan profit perusahaan. Pencapaian hasil yang optimal merupakan esensi dari pengelolaan sumber daya manusia, konkritnya adalah ada peningkatan produktivitas karyawan. Peningkatan produktivitas karyawan dapat dilakukan dengan banyak cara, antara lain dengan memberikan kompensasi baik finansial dan non finansial.

Pemberian kompensasi dalam pengelolaan manajemen sumber daya manusia dalam suatu organisasi ataupun perusahaan memang sangat penting adanya. Hal ini dikarenakan pemberian kompensasi kepada para karyawan atau pekerja memang sudah menjadi hak mereka. Pemberian kompensasi yang layak dapat meningkatkan kinerja para karyawan tersebut yang dimana pada akhirnya dapat sangat berpengaruh juga terhadap produktivitas yang dihasilkan.

Tingginya produktivitas kerja seorang karyawan bukanlah suatu hal yang kebetulan saja. Akan tetapi banyak faktor terkait yang mempengaruhi. Masalah kompensasi merupakan salah satu aspek yang paling berarti, baik karyawan maupun organisasi.
Kompensasi yang diberikan karyawan harus dapat memenuhi kebutuhan secara minimal sesuai dengan peraturan yang berlaku. Bila para karyawan memandang kompensasi tidak memadai maka produktivitas karyawan bisa turun. Agar produktivitas karyawan dapat meningkat perlu mendapat kompensasi baik finansial maupun non finansial.

\section{KAJIAN PUSTAKA}

\section{Pengertian Kompensasi Finansial}

Menurut Sunarto dalam Sunyoto (2012:31) bahwa kompensasi finansial adalah sesuatu yang diterima oleh karyawan dalam bentuk seperti gaji, upah, bonus, premi, tunjangan hari raya, tunjangan hari tua, pengobatan atau jaminan kesehatan, asuransi dan lain-lain yang sejenis yang dibayarkan oleh organisasi.

Kompensasi Finansial merupakan kompensasi yang dibayarkan langsung dan tidak langsung kepada karyawan.

\footnotetext{
Komponen kompensasi finansial Macam-macam kompensasi finansial yaitu :

a. Upah
} 
Upah merupakan uang yang dibayarkan sebagai pembalas jasa atau sebagai pembayar tenaga yang sudah dikeluarkan oleh perusahaan untuk mengerjakan sesuatu.

b. Insentif

Insentif merupakan tambahan-tambahan kompensasi diatas atau diluar gaji atau upah yang diberikan oleh perusahaan

c. Bonus

Bonus merupakan upah tambahan di luar gaji atau upah sebagai hadiah atau perangsang yang diberikan oleh perusahaan.

d. Tunjangan kesehatan

Tunjangan kesehatan merupakan bagian dari hasil penghasilan karyawan diluar gaji pokok.

e. Tunjangan pensiun

Tunjangan pensiun merupakan tunjangan jaminan hari tua dan sebagai balas jasa terhadap karyawan beserta keluarganya.

f. THR

THR merupakan tunjangan yang diberikan oleh perusahaan kepada karyawan agar bisa merayakan hari raya keagamaan dengan lebih indah dan hikmat.

\section{Pengertian Kompensasi Non Finansial} Menurut Rivai (2004:360)

Kompensasi non finansial merupakan bentuk kompensasi yang diberikan kepada karyawan selain dalam bentuk uang. Kompensasi non finansial merupakan kepuasan yang diperoleh seseorang dari pekerjaan itu sendiri atau dari lingkungan psikologis dan atau fisik dimana orang tersebut bekerja dan kepuasaan tersebut diperoleh dari pelaksanaan tugas-tugas yang bermakna yang berhubungan dengan pekerjaan.

\section{Komponen Kompensasi Non Finansial} Menurut Schuler dan Jackson dalam Wilson Bangun (2012:257), imbalan non finansial adalah berupa imbalan karir (berupa rasa aman, pengembangan karir, dan peluang kenaikan penghasilan), dan imbalan sosial (berupa: simbol status, pujian dan pengakuan, kenyamanan tugas, dan persahabatan). Dapat dikatakan bahwa, jenis kompensasi ini berkaitan dengan kepuasaan kerja yang diterima setiap pekerja. Kepuasan kerja yang diterima seorang pekerja tidak selamanya dapat dinyatakan dalam bentuk uang atau fasilitas-fasilitas fisik lainnnya.

Menurut Mondy (2008: 60), Komponen

kompensasi non finansial meliputi:

a. Jabatan itu sendiri terdapat lima dimensi jabatan inti, yaitu: variasi keterampilan, identitas tugas, signifikansi tugas, otonomi dan umpan balik.

b. Lingkungan kerja seperti kebijakan yang baik, manajer yang berkemampuan, karyawan yang kompeten, rekan kerja yang bersahabat, simbol status yang pantas dan kondisi kerja.

\section{Pengertian Produktivitas}

Setiap organisasi baik berbentuk perusahaan maupun lainnya akan selalu berupaya agar para anggota atau pekerja yang terlibat dalam kegiatan organisasi dapat memberikan prestasi dalam bentuk produktivitas kerja yang tinggi untuk mewujudkan tujuan yang telah ditetapkan. Menurut Siagian (2006:105) menyatakan bahwa "produktivitas itu dipengaruhi oleh motivasi dan etos kerja, keterampilan dan kualitas tenaga kerja, pengupahan dan jaminan social". Menurut Hasibuan (2007:108) menyatakan bahwa "produktivitas adalah perbandingan antara output (hasil) dengan input (masukan). Jika produktivitas naik ini hanya dimungkinkan oleh adanya peningkatan efisiensi (waktu,bahan, tenaga) dan sistem kerja, teknik produksi, dan adanya peningkatan keterampilan dari tenaga kerja”.

\section{Indikator Produktivitas Kerja}

Produktivitas merupakan hal yang sangat penting bagi para karyawan di dalam perusahaan. Dengan adanya produktivitas kerja, diharapkan pekerjaan akan terlaksana secara efisien dan efektif sehingga pencapaian tujuan yang sudah ditetapkan dapat terlaksana. Untuk mengukur produktivitas kerja karyawan, diperlukan suatu indikator. Menurut Sutrisno (2010:104), indikator yang dapat digunakan untuk mengukur produktivitas kerja karyawan terdiri dari:

1. Kemampuan, yaitu kemampuan untuk melaksanankan tugas. Kemampuan seorang karyawan sangat bergantung pada keterampilan yang dimiliki serta profesionalisme dalam bekerja yang memberikan daya untuk menyelesaikan tugas-tugas yang diembankan kepadanya.

2. Meningkatkan hasil yang dicapai, yaitu 
berusaha meningkatkan hasil yang dicapai. Hasil merupakan salah satu yang dapat dirasakan, baik oleh yang mengerjakan maupun yang menikmati hasil pekerjaan.

3. Semangat kerja, yaitu usaha untuk lebih baik dari hari kemarin. Semangat kerja dapat dilihat dari etos kerja dan hasil yang dicapai dalam satu hari kemudian dibandingkan dengan hari sebelumnya.

4. Pengembangan diri, yaitu mengembangkan diri untuk meningkatkan kemampuan kerja. Pengembangan diri dapat dilakukan dengan melihat tantangan dan harapan dengan apa yang akan dihadapi.

5. Mutu, yaitu selalu berusaha untuk meningkatkan mutu lebih baik dari yang telah lalu. Mutu merupakan hasil pekerjaan yang dapat menunjukkan kualitas seorang karyawan. Meningkatkan mutu bertujuan untuk memberikan hasil yang terbaik yang akan sangat berguna bagi perusahaan dan diri sendiri.

6. Efisiensi, yaitu perbandingan antara hasil yang dicapai dengan keseluruhan sumber daya yang digunakan. Input dan output merupakan aspek produktivitas yang memberikan pengaruh cukup signifikan bagi karyawan.

Adapaun kerangka konseptual dalam penelitian ini adalah sebagai berikut

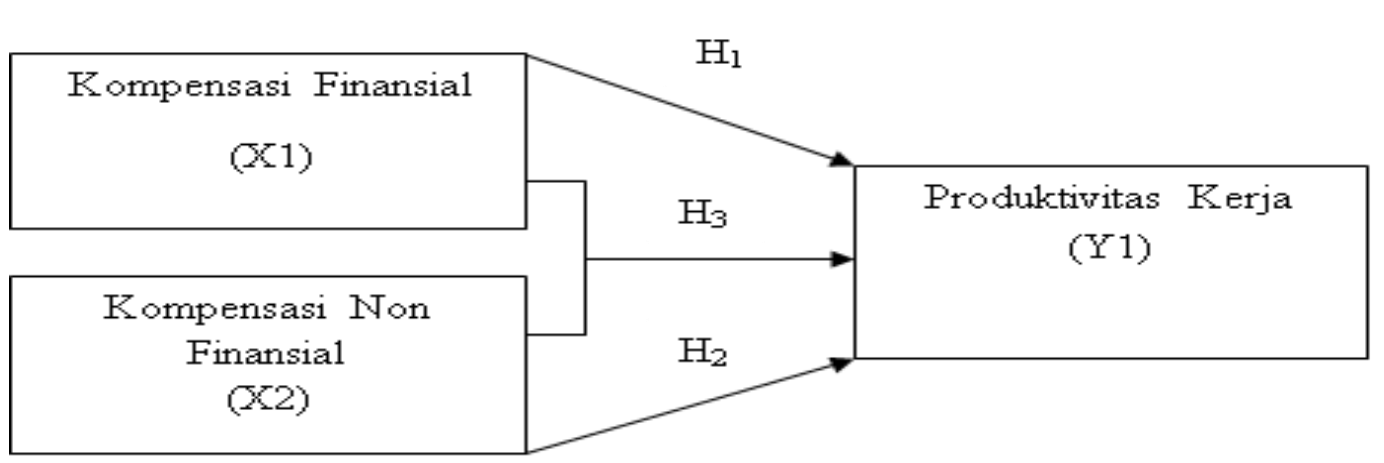

Gambar 1. Kerangka Konseptual

\section{METODELOGI PENELITIAN}

Penelitian ini menggunakan teknik sampling jenuh, yaitu teknik penentuan sampel yang dimana semua anggota populasi digunakan sebagai sampel dengan menggunakan kuesioner sebagai alat pengumpulan data dan secara umum menggunakan metode statistik. Populasi dalam penelitian ini adalah seluruh karyawan Bank Sumut Cabang Syariah Medan. Menurut Sugiyono (2012:122) sampel jenuh adalah "teknik penentuan sampel bila semua anggota populasi digunakan sebagai sampel.

Variabel bebas dalam penelitian ini adalah Kompensasi Finansial $\left(\mathrm{X}_{1}\right)$, Kompensasi Non Finansial $\left(\mathrm{X}_{2}\right)$, sedangkan yang menjadi varibel terikat adalah Produktivitas Kerja (Y).
Model analisis data yang digunakan untuk menjawab hipotesis penelitian adalah analisi regresi linier berganda, dengan formulasi sebagai berikut:

$\mathbf{Y}=\mathbf{a}+\mathbf{b}_{1} \mathbf{X}_{1}+\mathbf{b}_{2} \mathbf{X}_{2}+\mathbf{e}$

Pengujian asumsi klasik perlu dilakukan untuk mengetahui apakah alat uji statistik regresi linier berganda dapat digunakan atau tidak.

\section{HASIL DAN PEMBAHASAN}

\section{Hasil Analisis Regresi Linier Berganda}

Untuk mengetahui pengaruh variabel bebas Kompensasi Finansial dan Kompensasi Non Finansial serta variabel terikat Produktivitas Kerja dapat dilihat pada tabel 1 berikut: 
Tabel 1

Coefficients $^{\mathrm{a}}$

Tabel Hasil Uji Regresi Linier Berganda

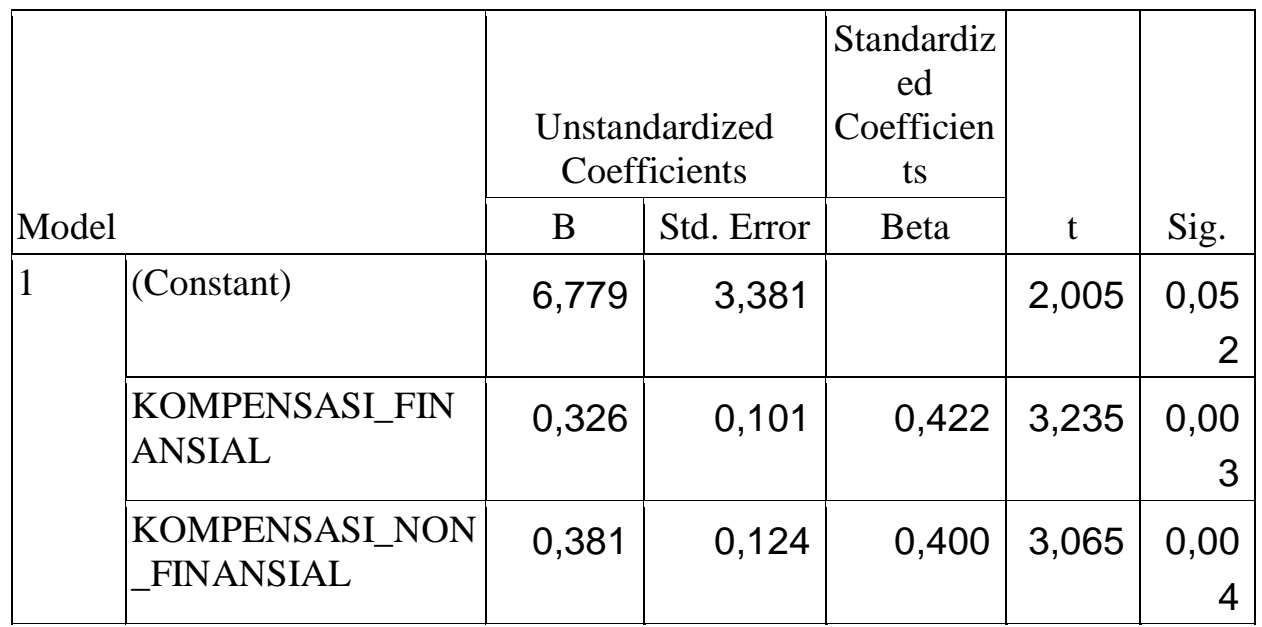

\section{a. Dependent Variable:}

PRODUKTIVITAS

Berdasarkan hasil pengolahan data seperti Tabel 1, diperoleh persamaan linier berganda sebagai berikut : $\mathbf{Y}=\mathbf{6 , 7 7 9}+$ $0,326 X_{1}+0,381 X_{2}$

Pada persamaan tersebut dapat dilihat bahwa Kompensasi Finansial $\left(\mathrm{X}_{1}\right)$ dan Kompensasi Non Finansial $\left(\mathrm{X}_{2}\right)$ mempunyai koefisien regresi positif yang membuktikan adanya konstribusinya terhadap Produktivitas (Y) pada Bank Sumut Cabang Syariah
Medan. Hal ini menunjukkan bahwa Produktivitas (Y) pada Bank Sumut Cabang Syariah Medan dapat dipengaruhi oleh Kompensasi Finansial dan Kompensasi Non Finansial.

\section{Uji t}

Hasil pengujian secara parsial dapat dilihat pada tabel 2 berikut:

Tabel 2

Hasil Uji t

\begin{tabular}{|c|l|c|c|}
\hline \multicolumn{2}{|c|}{ Model } & t & \multicolumn{1}{c|}{ Sig. } \\
\hline 1 & $($ Constant $)$ & 2,005 &, 052 \\
\hline & Kompensasi Finansial & 3,235 &, 003 \\
\hline & $\begin{array}{l}\text { Kompensasi Non } \\
\text { Finansial }\end{array}$ & 3,065 &, 004 \\
\hline
\end{tabular}

Dilihat dari Tabel 2. hasil Uji t (Uji Parsial) pada masing-masing variabel adalah sebagai berikut:

Nilai $t_{\text {hitung }}$ variabel kompensasi finansial adalah 3,235 dan nilai $t_{\text {tabel }}$ 2,026 maka $t_{\text {hitung }}>t_{\text {tabel }} \quad(3,235>2,026) \quad$ sehingga dapat disimpulkan bahwa variabel kompensasi finansial berpengaruh positif dan signifikan $(0,003<0,05) \quad$ secara parsial terhadap
Produktivitas karyawan pada Bank Sumut Cabang Syariah Medan.

Nilai $t_{\text {hitung }}$ variabel Kompensasi Non Finansial adalah 3,065 dan nilai $t_{\text {tabel }} 2,026$ maka $t_{\text {hitung }}>t_{\text {tabel }}(3,065>2,026)$ sehingga dapat disimpulkan bahwa variable Kompensasi Non Finansial berpengaruh positif dan signifikan $(0,004<0,05) \quad$ secara parsial terhadap Produktivitas karyawan pada Bank Sumut Cabang Syariah Medan. 


\section{Uji Determinasi (Adjusted $\boldsymbol{R}^{2}$ )}

Uji koefisien determinan (Adjusted

$R^{2}$ ) digunakan untuk mengukur seberapa jauh kemampuan variabel bebas yang dimasukkan kedalam model untuk menjelaskan seberapa besar pengaruh variabel terikat.

Tabel 3

Koefisien Determinasi Hipotesis

\begin{tabular}{|c|c|c|c|c|}
\hline Model & $\mathrm{R}$ & $\mathrm{R}$ Square & Adjusted $\mathrm{R}$ Square & $\begin{array}{c}\text { Std. Error of the } \\
\text { Estimate }\end{array}$ \\
\hline 1 &, $615^{\mathrm{a}}$ &, 378 &, 344 & 1,091 \\
\hline
\end{tabular}

a Predictors: (Constant), kompensasi_finansial, kompensasi_non_finansial

b Dependent Variable: Produktivitas

Berdasarkan Tabel 3. diperoleh nilai koefisien determinasi Adjusted $R$ Square sebesar 0,344. Hal ini menunjukkan bahwa kemampuan variabel Kompensasi Finansial $\left(\mathrm{X}_{1}\right)$ dan Kompensasi Non Finansial $\left(\mathrm{X}_{2}\right)$ menjelaskan pengaruhnya terhadap variabel Produktivitas (Y) pada Bank Sumut Cabang Syariah Medan sebesar $34,4 \%$. Sedangkan sisanya sebesar
65,6\% merupakan pengaruh dari variabel bebas lainnya yang tidak diteliti dalam penelitian ini.

\section{Uji Signifikansi Simultan (Uji F)}

Hasil Pengujian secara simultan dapat dilihat pada tabel berikut:

Tabel 4

Uji F

\begin{tabular}{|c|c|r|r|r|r|r|}
\hline Model & & Sum of Squares & \multicolumn{1}{c|}{ df } & $\begin{array}{c}\text { Mean } \\
\text { Square }\end{array}$ & F & Sig. \\
\hline 1 & Regression & 26,732 & 2 & 13,366 & 11,228 & $\begin{array}{r}00 \\
0^{\text {a }}\end{array}$ \\
\hline & Residual & 44,043 & 37 & 1,190 & & \\
\hline & Total & 70,775 & 39 & & & \\
\hline
\end{tabular}

a Predictors: (Constant), kompensasi_finansial, kompensasi_non_finansial

b Dependent Variable: Produktivitas

Berdasarkan Tabel 4. di atas, diperoleh bahwa nilai $F_{\text {hitung }}$ adalah 11,228 dengan tingkat signifikansi $0,000^{\mathrm{a}}$, sedangkan $\mathrm{F}_{\text {tabel }}$ pada tingkat kepercayaan $95 \%(\alpha=5 \%)$ adalah 3,25. Dengan demikian bahwa $F_{\text {hitung }}>F_{\text {tabel }}$ dan tingkat signifikansi $(\rho=0,000<0,05)$. Hal ini menunjukkan bahwa hasil penelitian menerima hipotesis $\mathrm{H}_{3}$

\section{Pembahasan}

Pengujian hipotesis menyatakan bahwa kompensasi finansial dan nonfinansial berpengaruh signifikan terhadap produktivitas kerja karyawan Bank Sumut Cabang Syariah Medan. Artinya semakin baik kompensasi yang diberikan perusahaan maka semakin yang artinya variabel bebas yakni, Kompensasi Finansial dan Kompensasi Non Finansial secara serempak berpengaruh positif dan signifikan terhadap variabel terikat, yakni Produktivitas pada Bank Sumut Cabang Syariah Medan.

meningkat pula produktivitas kerja karyawan pada Bank Sumut Cabang Syariah Medan.

Hasil penelitian ini mendapatkan hasil bahwa produktivitas dapat dipengaruhi oleh kompensasi finansial dan nonfinansial. Diperoleh bahwa $34,4 \%$ produktivitas kerja karyawan dapat dijelaskan oleh kedua variabel tersebut. Sejalan dengan penelitian 
yang dilakukan oleh Sumampouw (2013) yang meneliti di PT. Bank Tabungan Pensiunan Nasional Tbk Manado bahwa kompensasi berpengaruh signifikan terhadap produktivitas kerja karyawan dan pengaruhnya sebesar $59,6 \%$.

Di dalam penelitian ini hasil pengujian variabel kompensasi finansial dapat disimpulkan bahwa variabel kompensasi finansial berpengaruh secara positif dan signifikan terhadap produktivitas kerja karyawan Bank Sumut Cabang Syariah Medan. Hal ini terbukti pada nilai t hitung $(3,235)$ lebih besar dari t tabel $(2,026)$ dengan nilai signifikansi 0,003 dengan menggunakan batas signifikansi 0,05 . Pembuktian hipotesis menunjukkan bahwa kompensasi finansial memiliki pengaruh yang signifikan terhadap produktivitas karyawan. Dengan pemberian kompensasi finansial yang baik, maka akan dapat meningkatkan produktivitas karyawan. Apabila kompensasi finansial yang diberikan dapat memenuhi kebutuhan karyawan maka karyawan akan memberikan hasil kerja yang positif. Dengan hasil kerja yang positif maka produktivitas karyawan Bank Sumut Cabang Syariah Medan akan semakin baik juga.

\section{KESIMPULAN}

Berdasarkan hasil penelitian dan pembahasan yang telah diuraikan sebelumnya, disimpulkan bahwa secara serempak kompensasi finansial dan non finansial berpengaruh signifikan terhadap produktivitas kerja karyawan Bank Sumut Cabang Syariah Medan. Hal ini menunjukkan bahwa produktivitas kerja karyawan Bank

\section{REFERENSI}

Agustini, Fauzia. 2011. Manajemen Sumber Daya Manusia Lanjutan: Pendekatan Pengelolaan Sumberdaya Manusia Sebagai Kompetinsi Inti Dalam Suatu Organisasi. Medan: Madenatera.

Ahmad Badillah Maulana. Pengaruh Kompensasi Terhadap Produktivitas Kerja Karyawan Pada PT. Bank Mandiri (Persero) Cab. Jakarta Pondok Indah. http://perpus.unpam.ac.id/index.php? $\mathrm{p}=$ show-detail\&id=6158 (diakses 25 Januari 2014)

Bangun, Wilson. 2012. Manajemen Sumber Daya Manusia. Jakarta: PT. Gelora Aksara Pratama.
Dari hasil pengujian variabel kompensasi non finansial dapat disimpulkan bahwa variabel kompensasi non finansial berpengaruh secara positif dan signifikan terhadap produktivitas kerja karyawan Bank Sumut Cabang Syariah Medan. Hal ini terbukti pada nilai t hitung $(3,065)$ lebih besar dari t tabel $(2,026)$ dengan signifikansi 0,0004 dengan menggunakan batas signifikansi 0,05. Pembuktian hipotesis menunjukkan bahwa kompensasi non finansial memiliki pengaruh yang signifikan terhadap produktivitas karyawan. Dengan pemberian kompensasi non finansial yang baik, maka akan dapat meningkatkan produktivitas karyawan. Kompensasi non finansial dapat menjadi dasar menuju terwujudnya karyawan yang loyal. Loyalitas karyawan dapat meningkat apabila perusahaan memberikan kompensasi non finansial yang baik. Dengan loyalitas yang meningkat maka produktivitas karyawan Bank Sumut Cabang Syariah Medan akan semakin baik juga.

Sumut Cabang Syariah Medan dapat dipengaruhi oleh kompensasi finansial dan non finansial. Secara parsial variabel kompensasi finansial lebih dominan daripada variabel kompensasi non finansial. Artinya variabel kompensasi finansial lebih berperan dalam mempengaruhi produktivitas kerja karyawan Bank Sumut Cabang Syariah Medan dibandingkan dengan variabel kompensasi non finansial.

Christine Lydia Sumampouw. Pengaruh Kompensasi Terhadap Produktivitas Kerja Karyawan PT. Bank Tabungan Pensiunan Nasional Tbk Manado. http://ejournal.unsrat.ac.id/index.php/ actadiurna/article/view/2436 (diakses 26 Januari 2014)

Dessler, Gary. 2007. Manajemen Sumber Daya Manusia. Jakarta: PT. Indeks.

Ghozali, Imam. 2005. Aplikasi Analisis Multivariate dengan Program SPSS. Semarang: Badan Penerbit Universitas Dipenogoro.

Hasibuan, Malayu S.P. 2007. Manajemen Sumber Daya Manusia. Edisi Revisi. Cetakan kesepuluh. Jakarta: PT. 
Bumi Aksara.

Jefrey N. Gordon. 2010. Kompensasi Eksekutif dan Corporate Governance di Perusahaan Keuangan. Available

Jonas Vlachos Stockholm. 2007. Apakah Manajer berakar membayar pekerja mereka lebih?. Available at http://papers.ssrn.com/sol3/papers.cf m?abstract id=1431263

Kuncoro, Mudrajad. 2003. Metode Riset Untuk Bisnis dan Ekonomi. Jakarta: Erlangga.

Mardalis. 2008. Metode Penelitian (Suatu Pendekatan Proposal). Edisi Pertama.

Tasikmalaya. Available at http://www.unigal.ac.id/ejurnal/html/i ndex.php?naon=254 (diakses 13 Februari 2014)

Ndraha, Taliziduhu. 2002. Pengantar Teori Pengembangan Sumber Daya Manusia. Jakarta: PT. Rineka Cipta.

Rivai, Veithzal. 2009. Manajemen Sumber Daya Manusia Untuk Perusahaan: Dari Teori ke praktik. Jakarta: PT. Raja Grafindo Parsada.

Siagian, Sondang P. 2006. Manajemen Sumber Daya Manusia. Jakarta: PT. Bumi Aksara.

Sinungan. 2009. Produktivitas Apa dan Bagaimana. Jakarta: Aksara Perdana at

http://papers.ssrn.com/sol3/papers.cf $\underline{m ? \text { abstract } i d=1431263}$

Cetakan kesepuluh. Jakarta: PT. Bumi Aksara.

Mondy, R.W. 2008. Manajemen Sumber Daya Manusia. Edisi Kesepuluh (terjemahan). Jakarta: Penerbit Erlangga.

Nandang Fauzi Rahman. Pengaruh Human Relation dan Kompensasi Terhadap Produktivitas Kerja Karyawan PT. $\begin{array}{llll}B N I & \text { Life } & K P M & 4\end{array}$ Press

Sugiyono. 2008. Metode Penelitian Bisnis (Pendekatan Kuantitatif, Kualitatif dan $R \& D)$. Cetakan keduabelas. Bandung: Alfabeta.

Sunyoto,Danang. 2012. Teori, Kuesioner, dan Analisis dan Analisis Data Sumber Daya Manusia. Yogyakarta: CAPS.

Suliyanto. 2006. Metode Riset Bisnis. Yogyakarta: Andi

Sutrisno, Edy. 2010. Manajemen Sumber Daya Manusia. Jakarta : Kencana.

Wibowo. 2011. Manajemen Kerja. Jakarta: Rajawali 